BBA 75682

\title{
IN VITRO STIMULATION OF INSULIN RELEASE BY NON- METABOLIZABLE, TRANSPORT-SPECIFIC AMINO ACIDS
}

HALVOR N. CHRISTENSEN, BO HELLMAN, AKE LERNMARK, JANOVE SEHLIN, HOWARD S. TAGER AND INGE-BERT TÄLJEDAL

Department of Biological Chemistry, The University of Michigan, Ann Avbor, Michigan (U.S.A.) and the Department of Histology, University of Umea, Umea (Sweden)

(Received March 23rd, 197I)

SUMMARY

The insulin-releasing ability and uptake characteristics of non-metabolizable, transport-specific amino acids were studied in an in vitro system, using microdissected pancreatic islets with more than $90 \% \beta$-cells.

Among the four stereoisomers of 2 -aminobicyclo(2,2,I)heptane-2-carboxylic acid $(\mathrm{BCH})$, only the $\mathrm{b}(-)$ form stimulated insulin release. This isomer is known as a specific substrate for transport system $\mathrm{L}$ in other cells. It was rapidly taken up by the islet cells and stimulated insulin release both in the presence and in the absence of glucose.

4-Amino-I-guanylpiperidine-4-carboxylic acid (GPA), a substrate for cationic transport systems, stimulated insulin release in the presence but not in the absence of glucose. In this respect GPA is similar to arginine. Like arginine, GPA also accumulated in the islet cells to yield distribution ratios well above unity.

The results are consonant with the previous hypothesis that amino acids stimulate insulin release by binding to specific transport molecules.

\section{INTRODUCTION}

The use of non-metabolizable model amino acids has been instrumental to the discrimination of specific transport systems in various cells ${ }^{1}$. For example, $\alpha$-aminoisobutyric acid was developed as a model substrate for transport System A, 2-aminobicyclo $(2,2, \mathrm{I})$ heptane-2-carboxylic acid $(\mathrm{BCH})$ as a leucine analogue with specificity for System L, and 4-amino-I-guanylpiperidine-4-carboxylic acid (GPA) as a model substrate for the system for cationic amino acids. The first of these was observed under certain conditions to stimulate the release of insulin from cultivated fetal pancreas (A. E. RENold et al., personal communication to H. N. ChRISTEnSEN, I968); the second substance was concurrently found to exert a hypoglycemic action ${ }^{2,5}$ and to elevate the level of immunologically reactive insulin ${ }^{1,2}$ in the intact rat. Subsequently, the amino acid was shown to behave as a functional analogue of leucine in stimulating the rise of the plasma insulin level in the $\operatorname{dog}^{3}$. More recently, GPA has been shown to stimulate increase of the plasma levels of both insulin and glucagon in the rat ${ }^{1}$ and the $\operatorname{dog}$ (S. S. Fajans, H. N. Christensen et al., unpublished work).

Abbreviations: $\mathrm{BCH}, 2$-aminobicyclo $(2,2, \mathrm{I})$ heptane-2-carboxylic acid; GPA, 4-aminoI-guanylpiperidine-4-carboxylic acid. 
Several natural amino acids, including leucine, are known to stimulate the in vitro release of insulin. It seemed therefore reasonable to attribute the effects of $\mathrm{BCH}$ to a direct action on the pancreatic $\beta$-cells. Since, furthermore, these model amino acids were designed as transport-specific substrates, insulin release was suggested to be triggered by the binding of amino acids to their specific transport molecules in the $\beta$-cell membrane ${ }^{2}$.

In the present paper, we test this hypothesis by studying the insulin-releasing potency of different $\mathrm{BCH}$ stereoisomers and of GPA in vitro. In addition, it was checked whether the pancreatic $\beta$-cells are able to transport these model substrates. To obtain results representative of the $\beta$-cells, islets were microdissected from obesehyperglycemic mice. These islets contain more than $90 \% \beta$-cells, which are known to respond adequately to all secretagogues tested including natural amino acids such as leucine and arginine.

\section{MATERIALS AND METHODS}

\section{Chemicals}

The synthesis, ${ }^{14} \mathrm{C}$ labelling and resolution of $\mathrm{BCH}$ were done as previously described ${ }^{4,5}$. Synthesis and ${ }^{14} \mathrm{C}$ labelling of GPA will be described elsewhere by one of us (H.N.C.). $\left[\mathrm{I}^{3}{ }^{3} \mathrm{H}\right] \mathrm{Mannitol}$ and $\left[6,6^{\prime}-{ }^{3} \mathrm{H}_{2}\right]$ sucrose were obtained from the Radiochemical Centre, Amersham, England. Crystalline mouse insulin was prepared by Novo Industri A/S, Copenhagen, Denmark. All other chemicals were commercially available reagents of analytical grade. Distilled and de-ionized water was used throughout.

\section{Isolation of islets}

Adult obese-hyperglycemic mice (gene symbol: obob) from the Umeå colony were starved overnight. Fresh pancreatic islets were isolated by free-hand microdissection ${ }^{6}$ in Krebs-Ringer buffer including $0.3-0.5 \%(\mathrm{w} / \mathrm{v})$ human serum albumin and equilibrated with $\mathrm{O}_{2}-\mathrm{CO}_{2}(95: 5, \mathrm{v} / \mathrm{v})$.

\section{Incubations}

All incubations were performed at $37^{\circ}$, using Krebs-Ringer buffer as basal medium. In studies of insulin release, incubation was first performed for $4^{\circ} \mathrm{min}$. Batches of 2 islets were then incubated in I I $5 \mu \mathrm{l}$ medium for a short initial period of 5 min (early phase) followed by incubation for $60 \mathrm{~min}$ (late phase) in $315 \mu \mathrm{l}$ medium. The amounts of insulin released were measured in samples of medium taken from the three incubation periods, allowing correction for insulin present in a minimum volume left from the preceding incubation period. Details of experiments are given in the legends to figures and tables.

In studies of amino acid uptake, islets were first incubated in basal medium. Batches of 10 islets were subsequently incubated with radioactive amino acid. In some experiments the medium also contained $\left[\mathrm{I}-{ }^{3} \mathrm{H}\right]$ mannitol or $\left[6,6{ }^{\prime}-{ }^{3} \mathrm{H}_{2}\right]$ sucrose, which made it possible to correct for contaminating label and label in the extracellular space (B. Hellman, J. SEhlin and I.-B. Täljedal, unpublished work). When extracellular markers were not used, the incubated islets were washed for $4 \times \mathbf{I} \mathrm{min}$ in ice-cold, non-radioactive medium ${ }^{7}$. The detailed composition of incubation media as well as the length of incubation times are given in the legends to figures and tables. 


\section{Insulin assay}

Insulin was assayed with the double-antibody method $^{8}$, using crystalline mouse insulin as standard.

\section{Determination of amino acid uptake}

After weighing (see below), the incubated islets were dissolved by incubation at room temperature in Ioo $\mu \mathrm{l}$ of hyamine for $45 \mathrm{~min}$. After addition of Io ml scintillation liquid (5 $\mathrm{g}$ of 2,5 -diphenyloxazole and $50 \mathrm{mg} \mathrm{I,4-bis-2-(5-phenyl-oxazolyl)benzene} \mathrm{in}$ I 1 of toluene), counting was carried out in a liquid scintillation spectrometer. The observed counts/min values were translated to mmoles of labelled substrate by comparison with external standards counted in parallel with the islets. These standards consisted of $5 \mu$ lincubation medium dissolved in Ioo $\mu$ l of hyamine. In double-label experiments the setting of the discriminators was such that less than $0.5 \%$ of the ${ }^{3} \mathrm{H}$ counts were also counted in the ${ }^{14} \mathrm{C}$ channel. Spill-over to the ${ }^{3} \mathrm{H}$ channel was $25 \%$ of the counts in the ${ }^{14} \mathrm{C}$ channel. The specific radioactivities were chosen to give approximately the same counts/min in either channel.

\section{Weighing of islets}

Incubated islets were placed on bits of aluminium foil and were gently freed of as much contaminating fluid as possible with the aid of a micropipette. After freeze-drying $\left(-40^{\circ}, 0.00 \mathrm{Im} \mathrm{Hg}\right)$ overnight, the islets were weighed on a quartzfibre balance . $^{9}$

\section{RESULTS}

\section{Experiments with $B C H$}

As shown in Table $\mathrm{I}$, a racemic mixture of $\mathrm{b}(+)-\mathrm{BCH}$ and $\mathrm{b}(-)-\mathrm{BCH}$ stimulated insulin release, whereas a mixture of $\mathrm{a}(+)-\mathrm{BCH}$ and $\mathrm{a}(-)-\mathrm{BCH}$ did not. The effect of $\mathrm{b}( \pm)-\mathrm{BCH}$ was obtained both in the absence and in the presence of glucose.

\section{TABLE I}

\section{EFFECTS OF $\mathrm{a}( \pm)-\mathrm{BCH}$ AND $\mathrm{b}( \pm)-\mathrm{BCH}$ ON INSULIN RELEASE}

Amounts of insulin released during $60 \mathrm{~min}$ of incubation are given as mean values \pm S.E. for the numbers of experiments indicated within parentheses. In each experiment islets from a single animal were incubated with 5 or $10 \mathrm{mM} \mathrm{BCH}$ as well as in a $\mathrm{BCH}$-free control medium. A statistical test of the mean differences between test and control media revealed that $\mathrm{b}( \pm)-\mathrm{BCH}$ had a significant effect both in the absence $(5 \mathrm{mM}: P<0.05 ;$ 10 $\mathrm{mM}: P<0.00 \mathrm{I})$ and in the presence ( Io $\mathrm{mM}: P<0.02$ ) of glucose.

\begin{tabular}{|c|c|c|c|}
\hline \multirow{2}{*}{$\begin{array}{l}\text { Glucose concn. } \\
(m M)\end{array}$} & \multicolumn{3}{|c|}{$n g$ insulin released per $\mu g$ dry islet } \\
\hline & $o m M$ amino acid & $5 m M$ amino acid & Io $m M$ amino acid \\
\hline \multicolumn{4}{|c|}{ Experiments with $b( \pm)-B C H$} \\
\hline o & $0.36 \pm 0.07(9)$ & I.OI $\pm 0.25(9)$ & I.92 七 $0.18(9)$ \\
\hline 10 & $8.09 \pm 1.12(9)$ & IO.I I \pm I.55 (9) & $\mathrm{I} 2.75 \pm \mathrm{I} .43(9)$ \\
\hline \multicolumn{4}{|c|}{ Experiments with a(土)-BCH } \\
\hline o & $0.55 \pm 0.20(8)$ & $0.56 \pm 0.16(8)$ & 一 \\
\hline 10 & $4.3^{8} \pm 0.5^{1}(8)$ & $4.03 \pm 0.3^{8}(8)$ & - \\
\hline
\end{tabular}


Table II shows the effects of isolated $b(-)-\mathrm{BCH}$ and $\mathrm{b}(+)-\mathrm{BCH}$ isomers. Whereas $\mathrm{b}(+)-\mathrm{BCH}$ failed to stimulate insulin release, significant effects were obtained both in 5 -min and $60-$ min incubations with $\mathrm{b}(-)-\mathrm{BCH}$. The effects of $\mathrm{b}(-)-\mathrm{BCH}$ did not require the presence of glucose. The relationship between the $\mathrm{b}(-)-\mathrm{BCH}$ concentration and the rate of insulin release is given in Fig. I. The dose-response relationship was apparently hyperbolic with maximum stimulation at about $20 \mathrm{mM}$ and an apparent $K_{m}$ of around $7 \mathrm{mM}$.

TABLE II

\section{EFFECTS OF $b(+)$-BCH AND $b(-)$-BCH ON INSULIN RELEASE}

Amounts of insulin released during the first 5 min (early phase) or subsequent 60 min (late phase) after exposure to $\mathrm{BCH}$ are given as mean values $\pm \mathrm{S}$. E. for the numbers of experiments indicated within parentheses. In each experiment islets from a single animal were incubated with $5 \mathrm{mM}$ $\mathrm{b}(+)-\mathrm{BCH}$ or $\mathrm{b}(-)-\mathrm{BCH}$ as well as in a $\mathrm{BCH}$-free medium. A statistical test of the mean differences between test and control media revealed that $\mathrm{b}(-)-\mathrm{BCH}$ had a significant effect both in the absence (early phase: $P<0.02$; late phase: $P<0.025$ ) and presence (late phase: $P<0.05$ ) of glucose.

\begin{tabular}{|c|c|c|c|}
\hline \multirow{2}{*}{$\begin{array}{l}\text { Glucose concn. } \\
(m M)\end{array}$} & \multicolumn{3}{|c|}{ ng insulin released per $\mu g d r y$ islet } \\
\hline & Control & $5 m M b(+)-B C H$ & $5 m M b(-)-B C H$ \\
\hline \multicolumn{4}{|l|}{ Early phase } \\
\hline 0 & o. I $2 \pm 0.03(9)$ & $0.19 \pm 0.06(10)$ & $0.37 \pm 0.08(\mathrm{IO})$ \\
\hline Io & $0.82 \pm 0$. II (IO) & $0.63 \pm 0.13(10)$ & $0.80 \pm 0.17(\mathrm{IO})$ \\
\hline I 7 & $0.88 \pm 0.17$ (Io) & - & - \\
\hline \multicolumn{4}{|l|}{ Late phase } \\
\hline o & $0.33 \pm 0.06(10)$ & $0.36 \pm 0.08$ (то) & $1.00 \pm 0.34(10)$ \\
\hline Io & $6.05 \pm 0.83(10)$ & $5.94 \pm 0.52(\mathrm{IO})$ & $8.24 \pm 0.87(10)$ \\
\hline I 7 & $8.75 \pm 0.79(10)$ & - & 一 \\
\hline
\end{tabular}
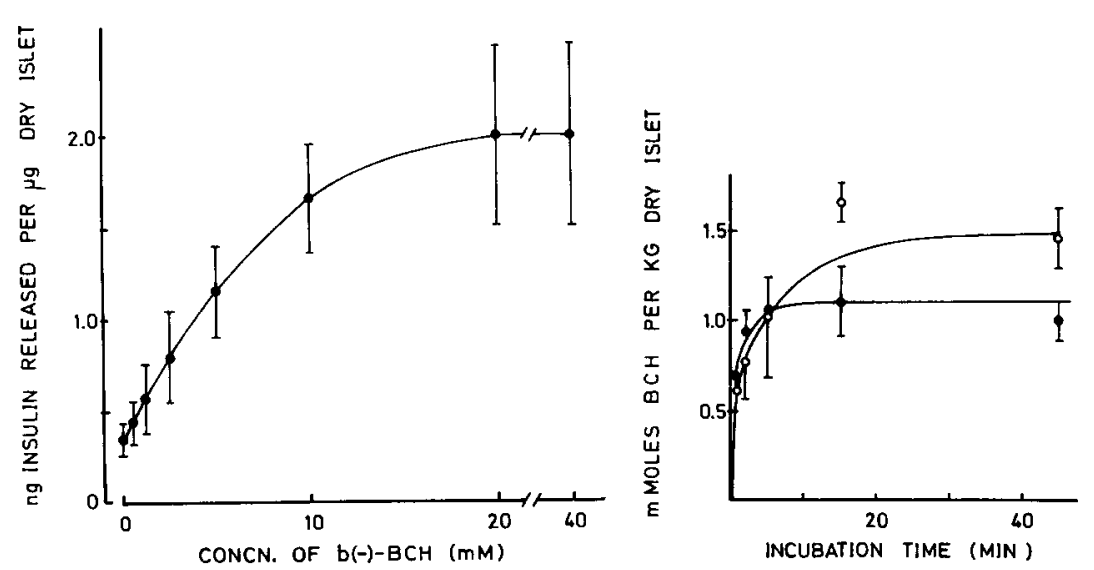

Fig. I. Concentration-dependency of insulin release in response to $b(-)$ - $\mathrm{BCH}$ during 60 min of incubation. Mean values \pm S.E. for $9-$ Io different experiments.

Fig. 2. Islet uptake of $b(+)-\mathrm{BCH}(\mathrm{O})$ and $\mathrm{b}(-)-\mathrm{BCH}(O)$ with time. After incubation for $30 \mathrm{~min}$ in glucose-free $\mathrm{KRB}$, islets were incubated for different periods of time in media containing I.o $\mathrm{mM}[$ carboxyl-14 $\mathrm{C}]-\mathrm{b}(+)-\mathrm{BCH}$ or $[$ carboxyl-14 $\mathrm{C}]-\mathrm{b}(-)-\mathrm{BCH}(\mathbf{I} .0 \mathrm{mC} / \mathrm{mmole})$, as well as $0.1 \mathrm{mM}$ $\left[\mathrm{I}^{3} \mathrm{H}\right]$ mannitol $(25.0 \mathrm{mC} / \mathrm{mmole})$. The amounts of $\mathrm{BCH}$ taken up by the islet cells were calculated by correction for label in the mannitol space. Mean values \pm S.E. for $4^{-1} 3$ observations. 
Islet uptake of $\mathrm{b}(+)-\mathrm{BCH}$ and $\mathrm{b}(-)-\mathrm{BCH}$ was studied in double-label experiments using $\left[\mathrm{I}^{-} \mathrm{H}\right]$ mannitol as extracellular marker. As shown in Fig. 2 , the islet content of either isomer rapidly exceeded that of mannitol, which suggests that both $\mathrm{b}(+)-\mathrm{BCH}$ and $\mathrm{b}(-)-\mathrm{BCH}$ were rapidly taken up by the $\beta$-cells. A statistical analysis of the results indicates that the level of $\mathrm{b}(+)-\mathrm{BCH}$ was probably higher than that of $\mathrm{b}(-)-\mathrm{BCH}$ after $45 \mathrm{~min}$ of incubation $(P<0.05)$.

\section{Experiments with GPA}

The effect of GPA on insulin release is presented in Table III. When tested at a concentration of $5 \mathrm{mM}$, the arginine analogue failed to enhance insulin release. A probably significant stimulation was, however, noted after 60 min of incubation with Io $\mathrm{mM} \mathrm{GPA}$ in the presence of Io $\mathrm{mM}$ glucose.

\section{TABLE III}

\section{EFFECT OF GPA ON INSULIN RELEASE}

Results are presented as in Table II. The effect of Io $\mathrm{mM} \mathrm{GPA}$ in the presence of Io mM glucose was probably significant $(P<0.05)$ during the late phase.

\begin{tabular}{|c|c|c|c|}
\hline \multirow{2}{*}{$\begin{array}{l}\text { Glucose concn. } \\
(m M)\end{array}$} & \multicolumn{3}{|c|}{$n g$ insulin released per $\mu g$ dry islet } \\
\hline & Control & $5 m M G P A$ & Io $m M G P A$ \\
\hline \multicolumn{4}{|l|}{ Early phase } \\
\hline o & $0.15 \pm 0.05(8)$ & $0.2 \mathrm{I} \pm 0.05(7)$ & $0.18 \pm 0.08(8)$ \\
\hline IO & $0.88 \pm 0.24(8)$ & $1.07 \pm 0.47(7)$ & $0.9 \mathrm{I} \pm 0.17(9)$ \\
\hline \multicolumn{4}{|l|}{ Late phase } \\
\hline o & $0.34 \pm 0.08(9)$ & $0.5^{\circ} \pm 0.18(8)$ & $0.4^{8} \pm 0.16(8)$ \\
\hline 10 & $5.60 \pm \mathrm{I} .68(9)$ & $5.11 \pm 0.4^{8(8)}$ & $9.13 \pm$ I.I6 (8) \\
\hline
\end{tabular}

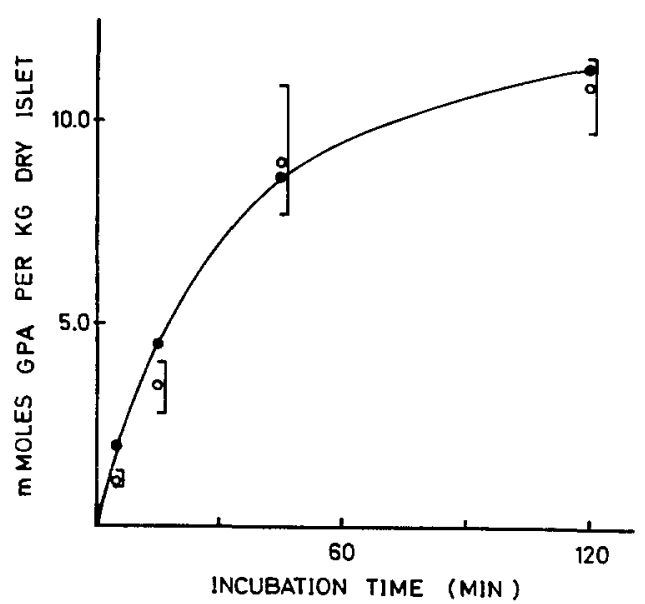

Fig. 3. Islet uptake of GPA with time. After incubation for $30 \mathrm{~min}$ in giucose-free KRB, islets were incubated for different periods of time in media containing $2.0 \mathrm{mM}$ [carboxyl-14C]GPA $(0.3 \mathrm{mC} / \mathrm{mmole})$. In one series of experiments $(O)$ the media also contained $\mathrm{o.I} \mathrm{mM}\left(6,6^{\prime}-{ }^{3} \mathrm{H}_{2}\right]^{-}$ sucrose $(20.0 \mathrm{mC} / \mathrm{mmole}$ ) as extracellular marker. The amounts of GPA taken up by the islet cells were in these experiments calculated by correction for label in the sucrose space. In another series of experiments (O) contaminating and extracellular label was removed by washing after incubation. Each point represents the mean of $2(0)$ or $3(0)$ different experiments. In addition, the range of observations in double-label experiments are given. 
Fig. 3 shows that the islet cells were able to accumulate GPA to yield distribution ratios much higher than unity. It should be noted that identical results were obtained irrespective of whether washing or double-labelling was used to correct for extracellular and contaminating radioactivity.

\section{DISCUSSION}

Several amino acids are able to stimulate insulin release ${ }^{10}$. Most of these, including arginine, do so in the presence of glucose, whereas leucine acts as a secretagogue also in glucose-free media ${ }^{11}$. The in vivo action of $\mathrm{BCH}$ resembles that of leucine and contrasts with that of arginine in persisting when mannoheptulose has been infused $^{3}$. Its hypoglycemic action was found to be limited to the $b(-)$-isomer of $\mathrm{BCH}^{1,5,12}$. The mechanism by which amino acids stimulate insulin release is not clear. The action of $\mathrm{BCH}$ in vivo indicates that the secretory response of the $\beta$-cells does not require metabolism of the amino $\operatorname{acid}^{1,2}$ (cf. ref. ro). As an alternative hypothesis, Christensen AND CUlLeN ${ }^{2}$ suggested that insulin release is triggered by the binding of amino acids to specific transport molecules in the $\beta$-cell membrane.

The present in vitro study was undertaken to elucidate the following problems that arise as a consequence of the above hypothesis. (I) Is $\mathrm{BCH}$-induced hypoglycemia due to a primary effect on the $\beta$-cells? (2) Are the $\beta$-cells stimulated by other transport-specific amino acids? (3) Is there a difference in insulin-releasing activity between the four stereo-isomers of $\mathrm{BCH}$ ? (4) Is there a correlation between the insulinreleasing activity of different $\mathrm{BCH}$ isomers and their uptake characteristics?

A direct effect of $\mathrm{BCH}$ on fetal rat pancreas has recently been described ${ }^{\mathbf{1 3}}$. This pancreas preparation differs, however, from adult islets in its sensitivity to various amino acids. For example, islets of obese-hyperglycemic mice are not stimulated by alanine or $\alpha$-aminoisobutyric acid ( $\AA$. Lernmark, unpublished work), whereas these amino acids are potent secretagogues with the fetal rat pancreas preparation ${ }^{13,14}$. Amino acids, not including $\mathrm{BCH}$ or leucine ${ }^{3}$, are also known to stimulate the release of glucagon ${ }^{10,15}$, which is in turn an insulin secretagogue. In the present study advantage was taken of the unusually low proportion of $\alpha$-cells in the microdissected islets of obese-hyperglycemic mice ${ }^{16}$. Our results are therefore most probably representative for the $\beta$-cells and support the idea that $\mathrm{BCH}$ exerts a direct stimulatory action on these cells.

If the hypothesis of CHRISTENSEN AND CULLEN ${ }^{2}$ is correct, one would expect a transport-specific arginine analogue to mimick arginine also as an insulin secretagogue. Circumstantial evidence that this is the case has been obtained by measuring plasma insulin in GPA-injected rats ${ }^{1}$ and dogs (S. S. Fajans, H. N. Christensen et al., unpublished work). From the present results it is clear that GPA is taken up by the islet cells and that it stimulates insulin release in vitro. The glucose dependency of GPA as an insulin secretagogue contrasts with the glucose independency of $b(-)$ $\mathrm{BCH}$ and supports the idea that GPA acts by the same mechanism as arginine. The fact that glucose also potentiates the effect of glucagon on insulin release ${ }^{17}$ stresses $^{-}$ the question whether the effect of GPA might be fully explained by its action as a glucagon secretagogue ${ }^{1}$. This possibility seems most unlikely, however, in view of the very low proportion of $\alpha$-cells in the present islets ${ }^{16}$.

$A$ racemic mixture of $b(+)-B C H$ and $b(-)-B C H$ stimulated insulin release significantly, whereas a similar mixture of $\mathrm{a}(+)-\mathrm{BCH}$ and $\mathrm{a}(-)-\mathrm{BCH}$ was without effect. 
It seems therefore unlikely that the a( $( \pm)$-isomers contribute to the hypoglycemic action of $\mathrm{BCH}$. After resolution of the individual b-isomers, it was evident that only $\mathrm{b}(-)-\mathrm{BCH}$ was effective as a stimulus of insulin release. With the latter isomer there was a significant enhancement of insulin release both in the absence and in the presence of glucose. In this respect, the behaviour of $\mathrm{b}(-)-\mathrm{BCH}$ is strikingly similar to leucine.

The structure of $\mathrm{BCH}$ was originally designed to provide a sufficiently bulky "side-chain" to keep it out of transport systems other than L. An incidental consequence of its structure is that the molecule not only escapes degradation but is subject to rather little distortion. The recognition site for insulin release obviously finds these characteristics no significant handicap and responds almost as though $\mathrm{BCH}$ were leucine; hence we are led to say that this recognition site resembles a transport site in not requiring that the "substrate" be either destabilized or distorted. It also resembles a transport site in finding only one of the four possible dispositions of the sidechain mass of $\mathrm{BCH}$ suitable to a response, namely that shown by the isomer $b(-)$. This isomer is the only one that shows measurable uptake by Escherichia coli, utilizing a transport system serving for leucine, isoleucine and valine ${ }^{1}$. The same isomer tends to have the most rapid uptake by various cells and tissues, and only it is regarded as a fully characteristic substrate of the so-called $\mathrm{L}$ system. Nevertheless, $\mathrm{b}(+)$ and $b(-)$ were taken up about equally rapidly by the isolated islets. In certain other tissues the $a(+)$-isomer has been shown in the Michigan laboratory to be transported approximately as well as the $b(-)$-isomer. We may of course question whether the same receptor site is involved for the two isomers in the two cases.

Because not much is known of recognition sites other than transport sites that need not degrade and perhaps not even to distort the substrate, it has been tempting to conclude that the site signalling insulin release is a transport receptor site, or is evolved from a transport receptor site ${ }^{2}$. This proposal did not specify which consequence of entry of a solute into a transport site might produce the signal, but presumably the response of the site, perhaps an induced fit to the substrate or a modification of conformational relations among participating macromolecules, is necessary to a signal. The circumstance that we now have uncovered an arginine-like insulin releasing agent in the first model substrate constructed for the transport system for cationic amino acids, and that this substrate is transported vigorously into the islet, encourages the same viewpoint. In the absence of a perfect correspondence between the amino acids that are transported and those that stimulate insulin release, however, only detailed analysis of the effector system can establish the hypothesis. For the present its main merit may be to provide us with a provisional example of the kind of recognition site needed to explain the signalling for insulin release.

\section{ACKNOWLEDGEMENTS}

This work was supported by the U.S. Public Health Service (AM-I2535; HD-or 233), the Swedish Medical Research Council (I2X-562; I2X-2288), and the Swedish Diabetes Association.

\section{REFERENCES}

I H. N. Christensen, Adv. Biochem. Psychopharm., in the press.

2 H. N. Christensen And A. M. Cullen, J. Biol. Chem., 244 (I969) I 52 I. 
3 S. S. Fajans, R. Qutbrero, G. L. Hallam, S. Pek, J. C. Floyd, Jr., H. N. Christensen and J. W. Conn, J. Clin. Endocrinol. Metab., in the press.

4 H. N. Christensen, M. E. Handlogten, I. Lam, H. S. Tager and R. Zand, J. Biol. Chem., 244 (1969) I5IO.

5 H. S. Tager and H. N. Christensen, Biochem. Biophys. Res. Commun., in the press.

6 C. Hellerström, Acta Endocrinol., 45 (1964) i 22.

7 B. Hellman, J. Sehlin and I.-B. TÄlJedal, Diabetologia, in the press.

8 C. N. Hales and P. J. Randle, Biochem. $J$., 88 (I963) I 37.

9 O. H. Lowry, $J$. Histochem. Cytochem., I (1953) 420.

io S. S. Fajans, J. C. Floyd J R., R. F. Knopf and J. W. Conn, Recent Prog. Horm. Res., 23 (I967) 6r7.

I I R. D. G. Milner, J. Endocrinol., 47 (1970) 347.

i 2 H. S. Tager, H. N. Christensen, A. M. Cullen, S. S. Fajans, S. Pek and R. Zand, Fed. Proc., 28 (1969) 574.

I3 A. E. Lambert, Y. Kanazawa, L. Orci and H. N. Christensen, Diabetologia, 6 (1970) 635.

I4 A. E. LAmbert, Biochemical and Morphological Studies of Cultured Fetal Rat Pancreas, Thesis, University of Louvain, I97o.

i5 R. H. Unger and A. M. Eisentraut, in S. Falkmer, B. Hellman and I.-B. Täljedal, The Structure and Metabolism of the Pancreatic Islets, Pergamon Press, Oxford, 1970, p. I4I.

i6 B. Hellman, Ann. N.Y. Acad. Sci., I3I (I965) 541 .

I7 H. G. Coore, B. Hellman, L.-A. Idahl and I.-B. Täljedal, Opusc. Med., I 2 (1967) 285.

Biochim. Biophys. Acta, 24I (I97I) 34I-348 